\title{
Towards Interoperability in Municipal Government: A Study of Information Sharing Practices
}

\author{
Stacy F. Hobson, Rangachari Anand, Jeaha Yang, and Juhnyoung Lee \\ IBM T. J. Watson Research Center, \\ Hawthorne, New York, USA \\ \{stacypre, ranand, jeaha, jyl\}@us.ibm.com
}

\begin{abstract}
Municipal governments rely heavily on the sharing of data between departments as a means to provide high-quality and timely service to its citizens. Common tasks such as parcel renovations require the involvement of multiple departments such as Building, Planning, Zoning, Assessment and Tax to achieve the ultimate goals. However, the software applications used to support the work of these departments are provided by independent software vendors and are not integrated with one another. Therefore, municipal employees rely heavily on manual methods for data sharing. We conducted a study of 12 municipal governments to understand their information sharing needs and practices. We focused on the interaction and information sharing within and between municipal departments. Our findings can be used to shape future research on e-government initiatives and interoperability of municipal applications.
\end{abstract}

Keywords: Information Sharing, Cooperative Work, Municipal Government, e-government.

\section{Introduction}

Citizens rely on municipal governments for the provisioning of services that cannot be achieved by an individual alone. These services include protection, maintenance of public areas and highways, environmental planning, safety, and governance. To this end, municipalities organize their internal department structure around specific service sub-areas. Departments such as police, fire, emergency services, and justice are responsible for services under the domain of protection. The sharing of information is essential for workloads that are divided across multiple people, departments and disparate applications. Information sharing between departments is used to help manage resources, communicate essential information about citizens and services, support the provisioning of services, and is useful in crime prevention efforts.

Departmental employees are expected to collaborate with other departments as needed, e.g. as mandated by policy or laws or in support of citizen-based services that span multiple departments. However, the information technology structure prevalent in most municipal governments does not easily support information sharing practices. IT applications that are interoperable can help in reducing employee workload, and also the expenses associated with and errors stemming from the manual transfer of data. 
Hoogenveen points out that municipal police departments often have database systems that are central to their work and used by their personnel, but lack an efficient manner to share information with other departments [12]. Atabakhsh supports this assertion and states that the necessary tools for data retrieval, filtering, integration and presentation have not been sufficiently developed [1].

Our research goal is to identify methods and design technologies that will increase employee efficiency and help reduce costs in the municipal government domain. As part of this, we noted how the intersection of IT applications, organizational structure, aspects of social interactions and internal policy all worked together to influence the level of collaboration and information sharing between municipal departments. To this end, we conducted a year-long study of 12 municipalities, focusing on the working practices of employees, the use of IT applications as work aids, the associated manual and IT-supported flow of information, the departmental structure and division of service responsibilities across municipal departments.

\subsection{Related Work}

Information sharing is a common topic of discussion in the HCI-related literature. There have been extensive studies on information sharing practices in the private sector, e.g. within enterprises and between independent groups $[2,10,17,20]$. Research on information sharing in the public sector have largely been limited to criminal justice $[1,23]$ and health and social service organizations, e.g. medical services [25], public health agencies [1, 23], and homeless shelters [18]. These and other studies on information sharing in the public sector relate to interaction between independent agencies [7, 14, 16, 19]. The division of labor and need for collaboration in the public sector can occur at many levels, e.g. at the local departmental level, at a peer agency level (i.e. from one municipality of government organization to another), from an agency level to another agency lower or higher in the hierarchy (from municipality to county or state agency), and from one nation to another. We maintain that some of the issues prevalent in information sharing initiatives between government agencies are also present within municipalities, yet the nature of municipal government organizational and IT structures can contribute to additional barriers to information sharing. This discussion is detailed in Sections 2 and 3.

Other related works contribute to the discussion of the role of IT in public sector information sharing practices. In an extensive research report by Harvard University's Center for Business and Government [9], the authors state that despite advancement in IT the government domain, stovepipes continue to dominate. Stovepipes are defined as "an inability to communicate across boundaries, between bureaucratic organizations or databases, due to lack of interoperability across hardware, software, or data systems; professional and cultural norms that prohibit or discourage information sharing; or legal strictures against communication." The authors also report that IT can be used to facilitate information sharing between entities and holds extraordinary promise as a vehicle for combating stovepipes, but that additional study is necessary to illuminate other factors influencing information sharing, such as aspects related to social science, policy, and trust research.

Governments are also becoming increasingly interested in electronic government (or e-government) as a means to increase the quality of service to its citizens and 
support transparency in government while maintaining or even reducing costs. As part of e-government initiatives, municipal websites can be developed and leveraged to allow citizens to access forms, submit service requests, and check the status of their request online, rather than in-person, thereby reducing the workload of municipal employees. Interoperability of IT systems is reported as a critical factor for (successful) e-government initiatives $[7,15,24,26]$, since the information that is needed for municipal websites stems from multiple internal departments and must be consolidated, parsed and presented to the citizen as needed. Kaylor et. al [13] point out that municipalities are very interested in implementing e-government but that they may have to pick and choose which subset of services to implement because of their limited funding to support e-government initiatives and the high costs of the related technologies. The necessity of automatic sharing of data and interoperability between systems is a contributing factor to the significant cost of e-government technologies. Caffrey suggests that governments can be even more efficient and effective just based on integration and use of the information they already collect and maintain [4].

In [3], researchers at the University of Albany's Center for Technology in Government suggest that a number of factors are critical for governments to get full value out of the information that they collect, create and maintain. Two of these factors are integration of systems and the proper availability and use of information. In $[5,6,8]$ the researchers also describe some of the benefits governments will realize through the integration of systems and availability of information, which include help with program planning, service evaluation, decision making and delivery of services to citizens.

Since the service offerings, technology needs and IT innovations of the public sector differs greatly from that of the private sector [29], we chose to study information sharing in a critical yet often overlooked area of the public sector, municipal governments.

Norman states that computer systems used to help people must be built to fit the needs of the people, and that systems cannot work for collaborative groups unless there is a deep fundamental understanding of the people, groups and how they work [22]. In the municipal government domain, we noticed that many of the inherent disparities of the IT application offerings makes information sharing a unique challenge for municipal employees and do not adequately help the employees collaborate. However, since the provision and management of services involve multiple departments, collaboration and information sharing is critical to the employees' work. This motivates our interest in studying the current ways municipal employees collaborate, share information and use IT applications. It also supports our interest in designing technology solutions to better support work at the municipal level.

We extend the research on information sharing in the public sector by providing an examination of the practices within public sector organizations, specifically municipal governments, in the remainder of the paper and compare our findings with that of the prior research.

\section{Study Methodology}

We conducted a study of 12 local governments in New York State over a 14 month period. The governments included three cities, four towns, four villages and one county. We employed semi-structured group and individual interviews, discussions 
with municipal administrators and multiple direct observation sessions of the employees as they carried out their daily routines. The demographic makeup of the municipalities varied greatly; ranging from urban areas with a median household income of $\$ 29,000$ to suburban areas with a median household income of $\$ 160,000$. The populations of the municipalities ranged from approximately 10,000 to 65,000 people. The demographics of the governments were found to be related to the IT inventory assessment; we noted that municipalities with higher income levels or high populations had more modern IT systems and software, while municipalities whose demographics both fell in the low- to mid-range utilized more paper-based manual processing for record keeping and service management.

Although our study was limited to a few medium-sized municipalities in New York State, it has been reported by US government census data that municipalities in this state, and the northeast area of the United States are similar in power, structure and function [28], we believe that these findings may be extendable to other municipalities in the same size range throughout the state of New York and other neighboring states.

During the study we aimed to determine how services were provided and managed by the municipality including the division of service responsibilities across departments, and how information technology (IT) systems and paper documents were used to support service management. We focused on the use of IT software by employees to carry out their work, inter-departmental information sharing practices and we engaged in a detailed analysis of paper documents, especially those generated and used in the transfer of information from one department to another.

\subsection{Study Details}

The study was qualitative in nature, and employed direct observations of the employees as they carried out their day to day work along with semi-structured individual and group interviews. Study participants were identified and organized through municipal associations and conferences based on their willingness to be studied. Seventy-one employees were involved in the study, representing fifteen of the seventeen municipal departments ${ }^{1}$ (listed under the administrator) from Figure 1.

We began our studies by interviewing the administrator for the municipality. The interview questions focused on determining the administrator's view of the organization, the areas of concern with respect to collaboration and information sharing between departments, and his/her identification of the departments in which their work and the need to share information was deemed most critical. Some of the questions used in the interview included:

1. What are your short-term goals for your organization?

2. What are your long-term goals?

3. How is the measure of performance of the overall organization measured?

4. Are there different measures for department-level performance?

5. Describe some examples of information that is communicated between departments.

${ }^{1}$ Very few municipalities studied had an animal control department since this function was often handled by the police. Similarly, in most cases, the highway department function appeared under the department of public works. Both areas were determined to be independent departments in municipalities much larger than the ones we studied. 
6. How is this information currently communicated?

7. Is there a specific department that has a primary responsibility for this information, or is the responsibility shared between departments? (asked for each example)

8. What is your primary concern with communication between departments?

9. What are your additional concerns?

10. Which points of communication between departments are most critical to $<$ the previously identified performance measure $>$ ?

11. Which points of communication are most critical to the delivery of services to your citizens?

After the interview of the administrator, we did initial observations of the employees from various departments. We observed and interacted with as many departmental employees as the administrator, or the coordinator of our visit would allow. The employees were told that we were interested in understanding municipal operations and their views on the work aids available and used to help them carry out their work. We chose to introduce our study to the employees in this manner to try and reduce concerns prompted by our visit (e.g. concerns of possible downsizing or critical inspection of their work performance).

During our initial observations of their work, we asked general questions about their responsibilities, challenges in their work, work methods, use of technology, to understand the scope of their work. We also allowed the employees some leverage in steering the direction and duration of this part of the study, in an effort to engage their trust and not impede their normal work.

After the first observation, we interviewed the employee using questions similar to those asked of the administrator, with more focus at the department level and appended by questions related to technology and work aids. After this interview, we asked the employees if we could continue to watch them as they worked without interrupting them, to get a better understanding of the internal operations. During this observation, we focused on points of interaction of overlap with other employees related to information or knowledge requests. For example, we noted when employees called or received calls from other employees, when they emailed or printed information to give to other employees, and the type of information exchanged and/or requested. Separately, we also engaged in some of the social interactions between employees (we were fortunate to be invited to a few office parties and events) to determine whether work items were discussed and what work-related topics of interest were emerged in the conversations. The goal of the extended observation was to determine areas of information sharing that were not identified by the employees in the interviews, and to better understand the scope of the information sharing.

Detailed notes from the interviews and observations were taken by the study team, and copies of work items were obtained. These work items included the common paperwork and forms that were processed for each department, the reports that were generated, and the objects that requested by, transferred to and received from other departments. Confidentiality was not a significant concern since most information is covered under New York State's Freedom of Information Law (FOIL) [21]. Items that were deemed confidential or of a sensitive nature (e.g. personnel records, birth records, etc) were discussed but not viewed or obtained. 


\subsection{Organizational Structure}

During our study, we examined the organizational structure of each the municipalities and found that a similar basic structure emerged. The municipalities, regardless of size, provided a base set of services to its citizens and generally utilized a common departmental structure to support these services. We note that although local, county or state law may mandate the offering of certain services or the existing of specific employee positions, departmental structure is not mandated by law. Figure 1 shows the example of the common municipal structure we discovered. The departments highlighted in bold were present in all the municipalities, and as such, serves as the basic departmental structure. This basic structure contained only the departments that are most critical to municipal operations and included other service areas as subfunctions supported within the primary departments. The assignment of the subfunctional service areas to specific departments varied more than the primary organization itself; the sub-functional areas depicted in our figure represent one of the examples we encountered.

The six departments included in the base structure most often were present in small municipalities that did not serve a large population $(<30,000)$. Larger municipalities (population $>30,000$ ) tended to have a more expansive structure, which corresponds to all seventeen departments listed in the figure.

We must note that all municipalities do not follow this structure exactly; rather, this is the general organization that has emerged from the municipalities we studied and is used for service delivery to its citizens. Individual municipalities may use different names for the department, may combine two departments into a single department, or

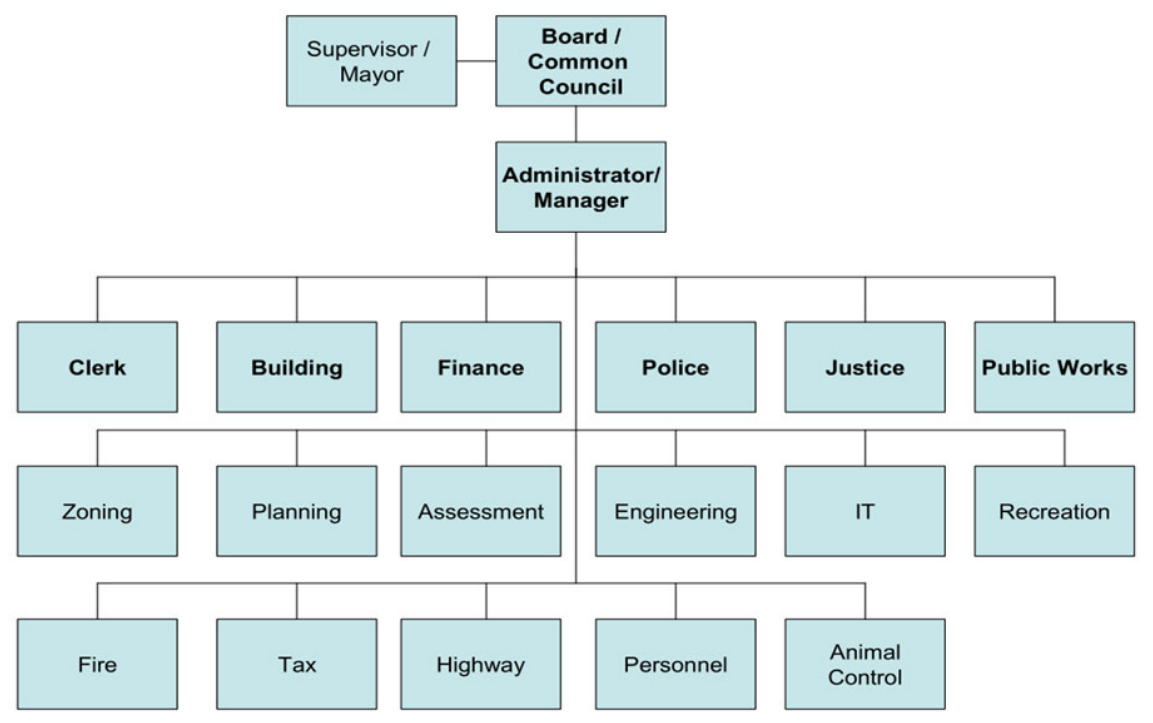

Fig. 1. Common Municipal Organization Structure 
vice versa, but the department's operational responsibilities and associated work tasks primarily align with the figures illustrated here. For example, the services provided by the Public Works department were available in each municipality, although the specific department name in a single municipality may have been Water and Sewer. We also note that the organization may have small differences stemming from municipal type. For example, while villages and cities have Fire Departments under their organizational structure, towns do not. Towns may organize special districts (outside of the town's internal organizational structure) to provide fire fighting services.

\subsection{Association of Organizational Structure and IT Applications}

Municipalities offer a range of services to its citizens, including protection, maintenance of roads and public areas, sanitation, and support programs. The internal departments are responsible for sub-sets of the service area offering and management functions. Seven types of service offerings are listed below along with the departments who jointly provide the services:

- $\quad$ Protective services - Police, Fire, Justice, Animal Control

- $\quad$ Sanitation/utilities - Public Works, Zoning, Engineering

- Environmental services - Public Works, Zoning, Engineering

- $\quad$ Support programs - Recreation, Clerk

- Internal programs - IT, Finance, Personnel

- Parcel management - Engineering, Building, Planning, Assessment, Tax, Clerk

- Personal services - Clerk, Justice, Police

Most of the IT applications used to support service delivery align directly to the departmental structure, with a single or multiple application(s) covering only the tasks associated with one department. However, services offered and provided to citizens often involve the work of many departments. Consider, for example, a parcel that has been recently renovated by its owners. The parcel owner applies for a building permit from the Building department. After the work has been completed and the Certificate of Occupancy has been issued, the Assessor's office must update the parcel details to reflect the renovations and initiate a parcel re-assessment. The newly assessed value has to be updated in the tax system for calculation of the property tax liability. Finally, the property tax payments collected by the tax department are directly entered into the tax system, and must later be updated in and reconciled with the accounts of the Finance department's General Ledger. This example describes the complex interactions between four departments as part of the administration for parcel management services including the renovations, assessment and property tax processes.

In many cases, the departments all use distinct, non-integrated, custom software programs to aid in their work. Additionally, departments may also use paper-based records and manual record-keeping. Figure 2 below shows the specific departmental and IT application structure from one of the municipalities we studied. Note that there are 10 different IT systems for the 8 departments, and that one additional department achieves their tasks entirely without the use of custom IT software (only through use of basic spreadsheet software and paper-based documentation methods). 


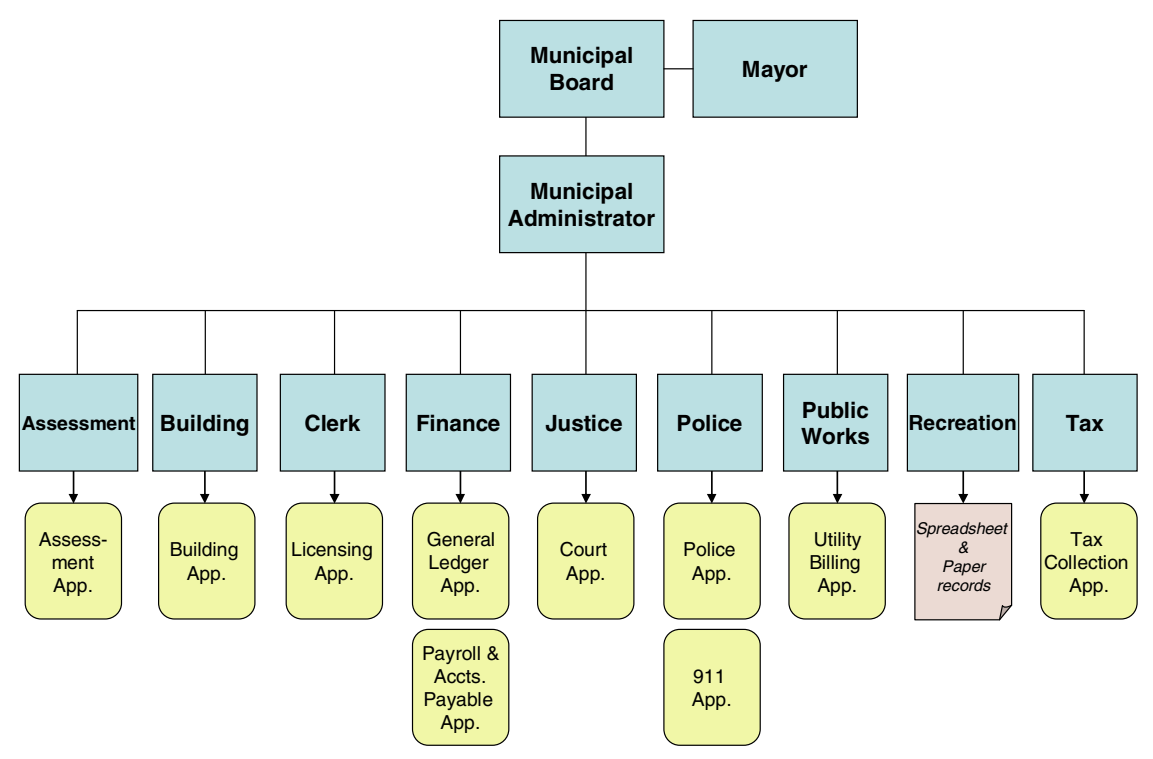

Fig. 2. Association of Department and IT applications

\section{Information Sharing Practices}

We introduced the notion of a common municipal structure and presented an example of the association of department and IT application in the previous sections as an introduction to the discussion on service boundaries. The types of information shared between departments can be static or dynamic. We define static information as information that is required and obtained by multiple groups, but remains unchanged in its representation or very minimally changed in its representation but unchanged in its function. We associate dynamic information with boundary objects. Boundary objects have been defined in the literature as objects that span multiple social worlds, are adaptable to satisfy the needs of each of these groups, while maintaining a common identity [27]. We consider departments within a municipality basic instances of social worlds. Examples of both types of information are described below.

Static information includes information at the data attribute level. For example, parcel contact details such as the mailing address, contact phone number, and owner name are items that often originate in a department such as building, assessment, or tax and must be shared throughout a large number of departments (building, zoning, assessment, tax, clerk, recreation, police and public works). Similarly, details related to property tax payments specifically amount due and/or payment amount, are communicated between the tax and finance department for accounting purposes, the tax and public works department for billing purposes (as a single bill for normal billing, or combined bill when a payment is overdue), and tax and recreation department for determination of eligibility requirements for certain recreation programs. 
In this case, boundary objects would include the information that originates in one department, and is passed on to other departments for additional viewing, processing, appending, and archiving. Specific examples include a building permit or renovation request, which is created by a user and internally originates from the building or zoning departments. This document is then shared with departments such building or zoning (whichever is not the originating department) and planning for purposes related to the evaluation and determination of the appropriateness of the renovation plans, the assessment department as the initializer of what then becomes the assessment, and then the tax department for the detailed tax liability and billing document.

Another example is seen with the communication documents that flow between the fire, police, emergency services (although external) and/or the justice departments. The boundary object in this case would be the incident or case report, the object that is used to document an event that has associations with public safety, a possible lawbreaking act, and/or in some cases, medical situations. Accuracy and timeliness in the transmission of this information is often critical for investigations, prosecution, and the prevention of future incidents or acts.

There are numerous challenges in the current methods for sharing of both types of information. An IT-specific challenge is related to the silo-ed nature of municipal applications (as described in the previous section). Significant manual work is often required to enable the transmission of information between departments when the IT does not support automatic sharing, and manual re-processing and re-keying of data can lead to omissions or data entry mistakes. Mistakes can have varying consequences from the extra time spent for identification and correction, up to a public safety disaster or threat. A deeper dive into some of the issues relating to information sharing within a single municipality is described below.

\subsection{A More Detailed Information Sharing Example}

Departments such as Police and Justice, Assessment and Tax, Personnel and Finance rely heavily on communication of data that is central to their work. The Police department must notify the Justice department of arrest and investigation details as input to current and future court cases. The Assessment department must periodically give the Tax department the tax roll, a listing of all taxable properties, their current assessment values, and valid exemptions. The Personnel department (and/or individual departments) maintains information on employee pay rates, raises, benefits, and work hours and these factors are used to calculate semi-monthly pay to produce payroll checks.

In one municipality, we found that 18 distinct pieces of information originating in the Tax department were shared with the Finance department for documentation and re-processing. Some of the information included printed records from the Tax application, documents that were generated in Microsoft Word or Excel as calculations data, and copies of bank slips for the tax payment deposits. Figure 3 shows the specific stack of information that the Tax department gives to the Finance department on a monthly basis. Much of this information is re-entered into the Finance application and then used for the process of monthly reconciliation with the bank statements. Figure 4 is a picture of the desk of the Finance department's manager, who is responsible for the reconciliation process. The three employees responsible for information sharing between the Tax and Finance departments spent about four total days per 


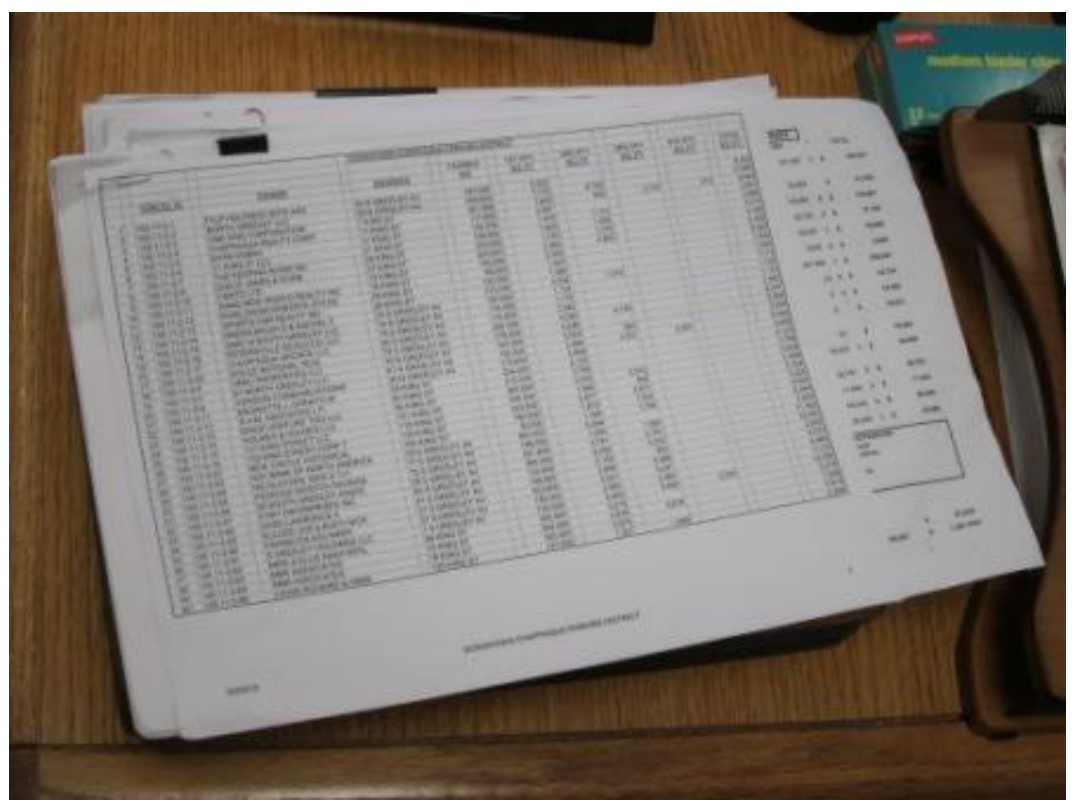

Fig. 3. Printed Records Transmitted from Tax to Finance Department

month (one day for each of the two tax employees, and two days for the finance employee) directly involved in this process; producing, transmitting, re-keying and correcting the associated data.

\subsection{Additional Factors Influencing Information Sharing}

So far, we have focused on the importance of intra-departmental information sharing in municipalities, and briefly described how the non-interoperability of IT applications influences the employees' methods of information sharing. We must also point out that municipalities may choose to pay for integration between two software programs or purchase pre-integrated software packages, especially for departments who share information frequently. This integration is useful in that it may reduce the amount of manual information sharing and processing that occurs and can allow for information to flow from one department to another automatically. However, the integration normally occurs between a set of applications and incurred very high costs for each pair (ranging from $\$ 8,000$ to $\$ 20,000$ ). This cost made it difficult for most of the municipalities we studied to afford more than a single integration.

We also determined that the organization of IT software can be a limiting factor for service offerings. During our study, a municipal administrator commented how information from the Clerk's department, e.g. animals registered to a specific parcel, can be useful to members of the Police and Fire departments when they are dispatched to the parcel for an investigation or emergency services. Currently, the primary way to have this information reflected in the Police or Fire department 


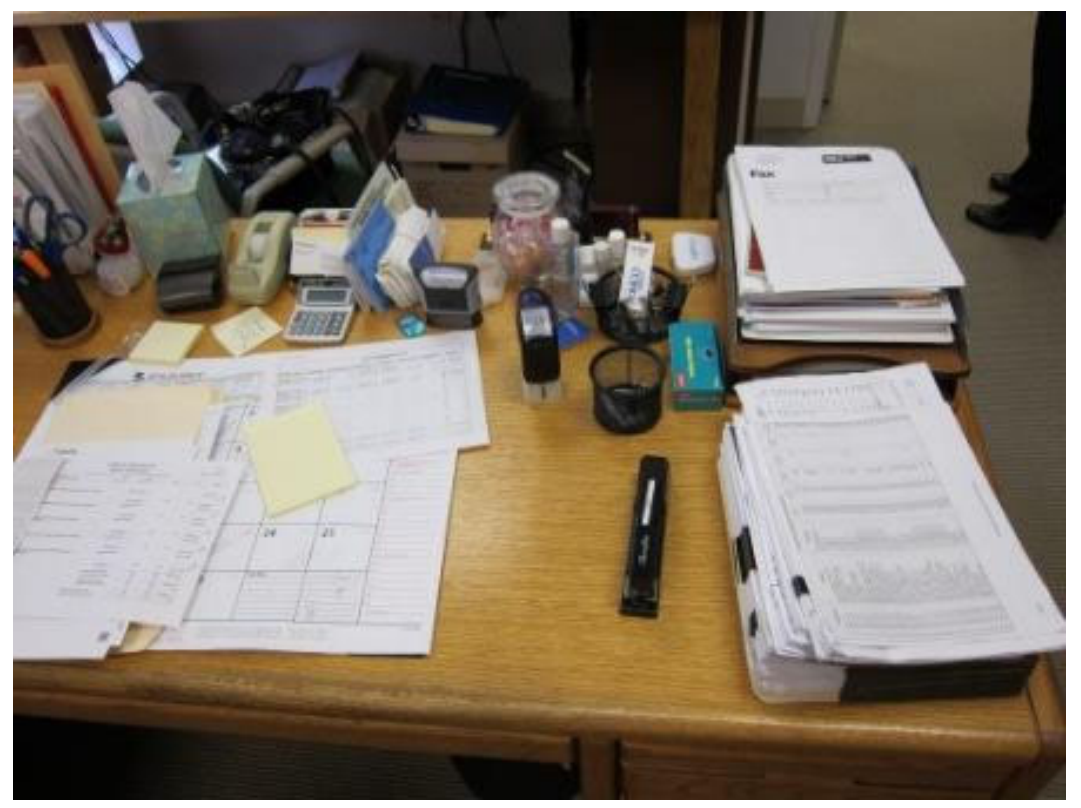

Fig. 4. Desk of Finance Employee with Records Awaiting Processing

software is through manual transmission and data entry. Since municipal workers are often overburdened with their general responsibilities, it is unlikely for this to occur on a regular basis, if ever.

In addition to the availability and usage of IT applications as an influence of information sharing practices, there are a number of other factors that may have an impact. We encountered a few cases where applications that included pre-integrated modules for multiple departments were evaluated and were either not chosen at all or only purchased for a subset of the departments. We discovered that this occurred for a number of reasons:

A preference for different non-integrated applications for each department. The department employees liked to have autonomy in choosing the applications that they used. An application was often chosen based on its suitability, familiarity, or ease-ofuse for a single department, with less emphasis put on their integrative capabilities. In one municipality, a finance department director and tax department director both recommended different pre-integrated software packages that covered both departments. However, the ones recommended were most suitable to the recommender's department and not as well tailored for the other department. The directors ultimately each chose the separate module of the system that was self-recommended and continued to manually transfer their information.

A resistance to change or preference for current manual methods for sharing. An employee or multiple employees tried to prevent the purchase of packages that would allow electronic means for information sharing. We interviewed a director of the 
Justice department in one municipality and she stated that she "specifically chose a package that would not integrate with the police department's application because [she] wanted them to continue to provide information to and request information from [her] department as they were used to." (Additional analysis of the interviews from employees of both departments suggested an ongoing power struggle between the two departments.)

Cost as a prohibitive measure. He cost of the integrated application packages provided by a single vendor was higher than that of the individual applications provided by multiple differing vendors, or a preference to only purchase one application module from an integrated package and continue using existing applications for other departments.

We also note that additional social and personal factors such as trust, willingness to share knowledge, political beliefs and/or the existence of policies or laws on information sharing may all have varying limits of involvement.

\section{Discussion}

Many of the related literature described in Section 1.1 focus on information sharing practices between government organizations (inter-organizational information sharing) or information sharing in a single service area (like public health, public safety and social services). Our study has focused on information sharing within public sectors organizations, specifically, in the municipal government domain. In the previous sections, we described IT application silos as one of the barriers to easy and effective information sharing within municipal governments. We maintain that the cause of and suggested solutions to application silo issues in municipal government differ than that of other areas. It is understandable that a challenge with inter-organizational information sharing is caused by silo-ed IT applications because the participating organizations are distinct and independently run, and are more likely to purchase IT applications without consulting one another. However, municipal governments are primarily governed by a single body (a mayor, supervisor, or board/council) and have motivations for intra-organizational information sharing (improvements in quality of citizen-based services and policies/dictates by management). Yet, municipal departments are still able to function very independently and make decisions that further inhibit information sharing efforts.

Additionally, domains like public health, public safety and social services are usually discussed with an inter-organizational information sharing focus. The discussions that do focus on intra-organizational cases occur at levels higher than municipal governments. For example, in the US, social services and public health offerings are county or state-based and not handled by municipal governments (with the exception of very few extremely large cities like New York City). Significant challenges for public health, social services and other higher level government organizations include information privacy and strict policies on how and with whom data can be shared, and also where data is stored. This is less of a concern in municipal governments in that a great deal of the information (property tax details, assessments, building records, etc.) fall under the scope of Freedom of Information Laws [21] and therefore are publically accessible. 


\subsection{Implications for Future Systems}

There are many challenges to interoperability in government. Two of the biggest barriers are time and funding. Municipal employees are often overburdened with their normal day-to-day duties and lack the necessary time needed to do an introspection of their information sharing needs and capabilities. When information sharing through technology is desired, municipalities often lack the extensive funding needed to enable point to point integration of their existing systems. Additionally, in the limited cases where software vendors offer "pre-integrated" technologies or software that span multiple departments, the span usually does not encompass all the departments involved in service management to the citizens. A distinct example we noted in our study was related to a new software package for the use in the Building, Planning and Zoning departments. The software provided a single point-of-use for all three departments and limited the need for manual information sharing between the departments, two significant issues were noted. The first was that the employees had difficulty in becoming proficient in using the system. The system was so vast and many menus and options that were available were not relevant to the work of a single department. Secondly, as noted above, since the citizen-based services related to parcel renovations spanned six separate departments (Building, Planning, Zoning, Assessment, Tax and Finance), manual information sharing was still needed to provide details to the remaining three departments (Assessment, Tax and Finance). We do note that the integrated system did reduce the need for manual processing within the three departments it covered, but did not wholly solve the information sharing needs related to the parcel renovations process.

Another distinct challenge lies in the view of providing a system that integrates all the information residing in the municipality and makes it available to the user. This solution is not optimal in that it overwhelms the user with too much information, only some of which is applicable to their work. Although this would help reduce the need for manual information sharing, it increases the cognitive load of the user and the amount of time spent parsing the information to find the details that are relevant to them. Also, information sharing issues can occur within a single department (e.g. data access or data migration issues) because of the great reliance on outdated IT systems and manual work methods in municipal governments. Therefore, IT projects or initiatives that aim to address information sharing problems through comprehensive data integration must also consider the need to gain access to records that are stored in the old systems or in paper format, which presents its own challenges.

A final challenge is in enabling the solution to fit the needs of each government. Since the set of IT applications in each government differ greatly, any solution that is offered to enable automatic integrations must be flexible so that it does not require significant individual customizations, yet remain economically feasible.

\section{Conclusion and Future Work}

Based on this study, we are currently designing a technology that will use a cloudcomputing platform and hub-based integration capabilities to deliver municipal government IT services. We aim to improve municipal operations through increased quality of service and work efficiency from automatic information sharing capabilities, cost reductions from reduced labor, and the creation of advance analytic capabilities 
available through integrated data. The hub-based integration capability differs from the traditional pair-wise integration capabilities currently possible within municipal governments. While pair-wise integration attempts to generate a component or add-on to link specific pairs of applications, our idea leverages the use of an information hub that coordinates data and event sharing among all the applications. When a new application is added to the municipal application set, it only needs to follow the APIs and guidelines that the information hub provides, and it can then be integrated with all the other applications (as allowed through configurations by a municipal system administrator). The pair-wise integration technique is often ad-hoc and costly; our hub-based integration design is aimed to be automatic, easily configurable and much less expensive. The cost can be down from $\mathrm{N}^{2}$ (the expected cost for pair-wise integration across all applications) to $\mathrm{N}$. More detail on this approach is available in [11].

This paper has helped to highlight the importance of intra-departmental information sharing in municipalities. Specifically, it is critical to the timely achievement of work, quality delivery of citizen-based services, and reduction of labor and cost associated with data re-entry. Today's significant reliance on manual methods for information sharing can often lead to mistakes that negatively impact the organization. Our illumination and discussion of these issues can be used as a foundation for researchers and key stakeholders of government initiatives to design alternatives methods for information sharing for municipal organizations.

\section{References}

1. Atabakhsh, H., Larson, C., Peterson, T., Violette, C., Chen, H.: Information Sharing and Collaboration Policies within Government Agencies. In: Chen, H., Moore, R., Zeng, D.D., Leavitt, J. (eds.) ISI 2004. LNCS, vol. 3073, pp. 467-475. Springer, Heidelberg (2004)

2. Barua, A., Ravindran, S., Whinston, A.: Effective Intra-organizational Information Exchange. Journal of Information Science 23(3), 239-248 (1997)

3. Bloniarz, P., Canestraro, D., Cook, M., Cresswell, T., Dawes, S., LaVigne, M., Pardo, T., Scholl, J., Simon, S.: Insider's Guide to Using Information in Government. Center for Technology in Government, State University of New York at Albany, http: / / www.ctg.albany.edu/static/usinginfo/index.htm

4. Caffrey, L.: Information Sharing Between and Within Governments. Commonwealth Secretariat, London (1998)

5. Center for Technology in Government, State University of New York at Albany. Dealing With Data Seminar Summary, http://www.ctg.albany.edu/publications/ reports/what_rules_govern/what_rules_govern.pdf

6. Center for Technology in Government, State University of New York at Albany. What Rules Govern the Use of Information?, http://www.ctg.albany.edu/ publications/reports/dealing_with_data/dealing_with_data.pdf

7. Dawes, S.: Interagency information sharing: Expected benefits, manageable risks. Journal of Policy Analysis and Management 15(3), 377-394 (1996)

8. Dawes, S., Cresswell, A., Pardo, T.: From "Need to Know" to "Need to Share": Tangled Problems, Information Boundaries, and the Building of Public Sector Knowledge Networks. Public Administration Review 69(3), 392-402 (2009)

9. Fountain, J.: Information, Institutions and Governance: Advancing a Basic Social Science Research Program for Digital Government. Harvard University Press, Cambridge (2003) 
10. Goh, S.: Managing Effective Knowledge Transfer: an Integrative Framework and Some Practice Implications. Journal of Knowledge Management 6(1), 23-30 (2002)

11. Hobson, S., Anand, R., Yang, J., Lee, J.: Municipal Shared Services Cloud. To appear in Proceedings of the 2011 SRII Global Conference. IEEE Press, Los Alamitos (March 2011)

12. Hoogenveen, M., van der Meer, K.: Integration of Information Retrieval and Database Management in Support of Multi-media Police Work. Journal of Information Science 20(2), 79-87 (1994)

13. Kaylor, C., Deshazo, R., Van Eck, D.: Gauging e-government: A report on implementing services among American cities. Government Information Quarterly 18, 293-307 (2001)

14. Koch, M., Steckler, N., Delcambre, L., Tolle, T.: Examining Information Sharing Across Federal Agency Boundaries. Presented at the National Workshop on Digital Government, Kennedy School of Government. Harvard University Press, Cambridge (2002)

15. Klischewski, R., Scholl, H.: Information Quality as a Common Ground for Key Players in e-Government Integration and Interoperability. In: Proc. 39th HICSS. IEEE Press, Los Alamitos (2006)

16. Layne, K., Lee, J.: Developing fully functional e-government: A four-stage model. Government Information Quarterly 18, 122-136 (2001)

17. Lee, H., So, K., Tang, C.: The value of information sharing in a two-level supply chain. Management Science 46(5), 626-643 (2000)

18. Le Dantec, C., Edwards, W.: The View from the Trenches: Organization, Power and Technology at Two Nonprofit Homeless Outreach Centers. In: Proc. CSCW 2008, pp. 589-598. ACM Press, New York (2008)

19. Le Dantec, C., Edwards, W.: Across boundaries of influence and accountability: The multiple scales of public sector information systems. In: Proc. CHI 2010, pp. 627-636. ACM Press, New York (2010)

20. Li, J., Sikora, R., Shaw, M., Tan, G.: A strategic analysis of inter organizational information sharing. Decision Support 42(1), 251-266 (2006)

21. New York State Department of State Freedom of Information Laws, http://www . dos.state.ny.us/coog/foil2.html

22. Norman, D.: Collaborative Computing: Collaboration First, Computing Second. Communications of the ACM, 88-90 (1991)

23. Pardo, T., Gil-Garcia, J., Burke, G.: Sustainable Cross Boundary Information Sharing. In: Digital Government: Advanced Research and Case Studies, and Implementation, pp. 421438. Springer Press, New York (2008)

24. Scholl, H.: Interoperability in e-government: More than just smart middleware. In: Proc. 38th HICSS. IEEE Press, Los Alamitos (2005)

25. Schooley, B., Horan, T.: Towards end-to-end government performance management: Case study of Interorganizational Information Integration in Emergency Medical Services (EMS). Government Information Quarterly 24, 755-784 (2007)

26. Siegfried, T., Grabow, B., Druke, H.: Ten factors for Success for Local Community Egovernment. In: Traunmüller, R. (ed.) EGOV 2003. LNCS, vol. 2739, pp. 452-455. Springer, Heidelberg (2003)

27. Star, S., Griesemer, J.: Institutional Ecology, Translations and Boundary Objects: Amateurs and Professionals in Berkeley's Museum of Vertebrate Zoology, 1907-39. Social Studies of Science, vol. 19, pp. 387-420 (1989)

28. US Census Individual State Descriptions, http: / /www. census.gov/prod/2005pubs/gc021x2.pdf

29. West, D., Lu, J.: Comparing Technology Innovation in the Private and Public Sectors. The Brookings Institution, Washington, DC, USA (2009) 